\title{
Evaluation of the Effect of using Electrosurgery in Pulpectomy of Deciduous Teeth on Succedaneous Teeth: An Animal Study
}

\author{
${ }^{1}$ Rasoul Sahebalam, ${ }^{2}$ Alireza Sarraf, ${ }^{3}$ Mojtaba Abdollahi, ${ }^{4} \mathrm{Hamid}$ Jafarzadeh, ${ }^{5} \mathrm{Hamidreza}$ Rajati, ${ }^{6}$ Shankargouda Patil
}

\section{ABSTRACT}

Objectives: The aim of this study was to determine the probable side effects of electrosurgery in pulpectomy of deciduous teeth on succedaneous teeth in dogs.

Materials and methods: In this animal study, all maxillary and mandibular teeth at one side of five puppies' mouths were treated employing electrosurgical pulpectomy and were then compared with those of the other side treated using the conventional method. The electrosurgical dental electrode was placed in canals to the point of working length for the experimental group. After pulpectomy, the canals were filled with zinc oxide eugenol paste and the access cavity was restored with amalgam. The dogs remained under care until their successor teeth erupted and clinical examination was performed.

Results: The teeth treated employing electrosurgical pulpectomy presented natural appearance with no observable defects including enamel hypoplasia, diffuse opacities of enamel, demarcated opacities, and enamel discoloration.

Conclusion: Electrosurgical pulpectomy can be considered as an option for pulpectomy of deciduous teeth.

Keywords: Deciduous teeth, Electrocautery, Pulpectomy.

How to cite this article: Sahebalam R, Sarraf $A$, Abdollahi $M$, Jafarzadeh H, Rajati H, Patil SG. Evaluation of the Effect of using Electrosurgery in Pulpectomy of Deciduous Teeth on Succedaneous Teeth: An Animal Study. J Contemp Dent Pract 2015;16(3):183-186.

\footnotetext{
1,2Department of Pediatric Dentistry, Faculty of Dentistry Mashhad University of Medical Sciences, Mashhad, Iran

${ }^{3}$ Student Research Committee, Mashhad University of Medical Sciences, Mashhad, Iran

${ }^{4}$ Department of Endodontics, Faculty of Dentistry, Dental Research Center, Mashhad University of Medical Sciences Mashhad, Iran

${ }^{5}$ Department of Prosthodontics, Faculty of Dentistry, Mashhad University of Medical Sciences, Mashhad, Iran

${ }^{6}$ Department of Oral and Maxillofacial Pathology, MS Ramaiah Dental College and Hospital, MS Ramaiah Educational Campus, Bengaluru, Karnataka, India

Corresponding Author: Hamid Jafarzadeh, Associate Professor, Department of Endodontics, Faculty of Dentistry Dental Research Centre, Vakilabad Blvd, Mashhad-91735984 Iran, Phone: +98-51-38829501, e-mail: hamid_365@yahoo. com
}

\section{Source of support: Nil}

Conflict of interest: None

\section{INTRODUCTION}

The main aim of the pulp therapy in pediatrics is maintaining the oral health in addition to sustaining the normal and physiologic function of the structures. ${ }^{1}$ In spite of all the recent progress in prevention of dental caries and increased appreciation of the prominence of maintaining normal dentition, a lot of teeth are still lost prematurely. $^{2}$

Pulpectomy is basically a treatment that intends to preserve a pulpally involved primary tooth by omitting microorganisms and their products as well as assuring perfect seal of the root canals so that the deciduous teeth can fulfill its role until exfoliation occurs without hurting the replacement and/or affecting the health of the patient. ${ }^{3,4}$ This treatment, which commonly consists of cleaning, shaping, and obturation with a resorbable paste has been broadly carried out with considerable clinical success. $^{5}$

During pulpectomy procedure, the anatomic and normal physiologic features of deciduous teeth are likely to pose problems to the clinicians. Also, when the carious process progresses faster than the developing of reactionary dentin, blood vessels of the pulp widen and dispersed inflammatory cells become apparent. ${ }^{6}$ In this situation, application of conventional methods for elimination of pulp from root canals of posterior deciduous teeth may prove to be time-consuming. Also, long endodontic treatment sessions might be contraindicated when treating young children. ${ }^{5}$ In the sense of all considerations mentioned thus far, and some of the difficulties confronted while cleaning and shaping the root canal, an extensive search has been embarked on as to identify initiative materials, instruments, and techniques promising a faster and more effective way of achieving a prepared canal ready for obturation. ${ }^{78}$ As a substitute to the conventional methods of utilizing hand and rotary instruments, ${ }^{9-12}$ more recent approaches have applied laser ${ }^{5}$ and techniques involving ultrasonic or sonic equipments. ${ }^{13,14}$ 
Using electrosurgery in the pulpotomy of deciduous teeth as a non-pharmacological method has been well-backed and has been confirmed to be a suitable technique. ${ }^{15-18}$ Driven by the facts that the benefits of electrosurgery may similarly be achievable in pulpectomy and that the usage of electrosurgery might in fact have some undesirable implications on the succedaneous permanent teeth, the aim of this study was to determine the probable side effects of electrosurgery in pulpectomy of deciduous teeth on succedaneous teeth in dogs.

\section{MATERIALS AND METHODS}

Five puppies, aged 2 months with their permanent teeth having incomplete root formation were included in the study. The study was carried out at the Animal Laboratory of the Dental Research Center of Mashhad University of Medical Sciences (MUMS), Mashhad, Iran. The Research Council of MUMS approved the experiment (Registration number: 900340).

The appearance of all maxillary and mandibular teeth at one side of each dog, which had been treated by means of electrosurgical pulpectomies, were compared with those of the other side treated using the conventional method.

Before starting the procedure, the animals were premedicated by injection of antibiotics, $1 \mathrm{ml} / 10 \mathrm{~kg}$ body weight $(150 \mathrm{mg} / \mathrm{ml}$ Amoxicillin and $40 \mathrm{mg} / \mathrm{ml}$ Gentamicin sulfate) (Gentamox, Gerona, Spain). The animals were subsequently anesthetized with an intravenous injection of 10\% Ketamine (Alfasan, Woerden, Holland) ( $10 \mathrm{mg} / \mathrm{kg}$ body weight) and Xylazine hydrochloride (0.5 $\mathrm{mg} / \mathrm{kg}$ body weight) (Alfasan, Woerden, Holland) for 15 minutes to ensure the animals were unconscious during the procedure. They also received $5 \%$ Flunixin meglumine (Erfan Daru, Tehran, Iran) (1 mg/kg body weight) through an intravenous injection to effect analgesia. Periapical radiographs were also obtained to predetermine the working length (Fig. 1).

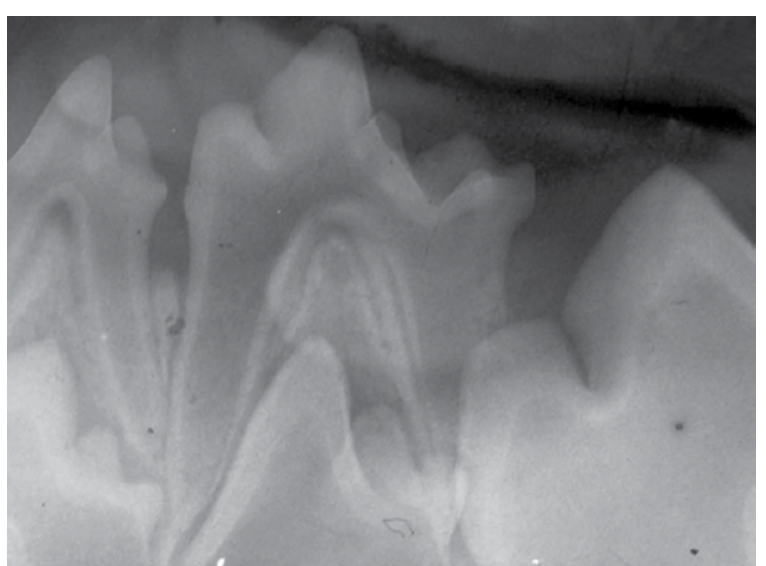

Fig. 1: Periapical radiograph for predetermining the working length
Upon rinsing the dogs' mouths with $0.2 \%$ chlorhexidine mouthwash (Shahrdaru, Tehran, Iran) and performing rubber dam isolation, access opening was achieved by utilizing a \#4 diamond bur (D + Z, Kalletal, Germany) under copious water spray; all overhanging dentin was eliminated from the roof of the pulp chamber. The coronal pulp tissue was removed using a round bur (D + Z, Kalletal, Germany). Barbed broaches (MEDIN, Nové Město na Mora, Czech Republic) were employed to remove the coronal pulp and hedstrom files (Dentsply, Maillefer, Ballaigues, Switzerland) up to \#40 to extirpate the radicular pulp. Iriigation was performed using $2.25 \%$ sodium hypochlorite. Finally, the canals were dried with sterile paper points (Ariadent, Tehran, Iran).

In the control group (conventional method), no other procedure was performed before filling the canal. As for the experimental group; however, once the dental electrosurgical needle-shaped electrode (Perfect, Coltene, Whaledent, USA) was placed in the canals to the working length and the electrosurgery unit's (Perfect, Coltene, Whaledent, USA) power was set at $40 \%$, electrical arc was used for length of 5 seconds or until canal bleeding stopped.

Finally, all canals were filled with zinc oxide eugenol paste (Golchadent, Tehran, Iran) and the access cavities were restored using amalgam restorations (Sinadent, Tehran, Iran).

All pulpectomy procedures were performed by the principal investigator (RS) to ensure consistency in both approaches. For the purpose of comparison, the dogs remained under care and inspection until their successor teeth erupted (5-7 months), so the teeth at two sides were evaluated for the effect of each method on succedaneous teeth.

Examination was performed under a dental operatory light (Pars Dental, Tehran, Iran) and the dentition was cleaned and dried using sterile gauze (Novin Band, Isfahan, Iran). All surfaces of each tooth were carefully inspected for any form of enamel hypoplasia, diffuse opacities of enamel, demarcated opacities, and any enamel discoloration.

\section{RESULTS}

During the study, the puppies were not affected by any diseases that might have had an undesirable effect on enamel. All of the teeth presented normally in terms of the time of eruption. Both the teeth treated using electrosurgical pulpectomy and those undergoing the conventional method erupted with no observable defects, including enamel hypoplasia, diffuse opacities of enamel, demarcated opacities, and any enamel discoloration (Figs 2 and 3). 


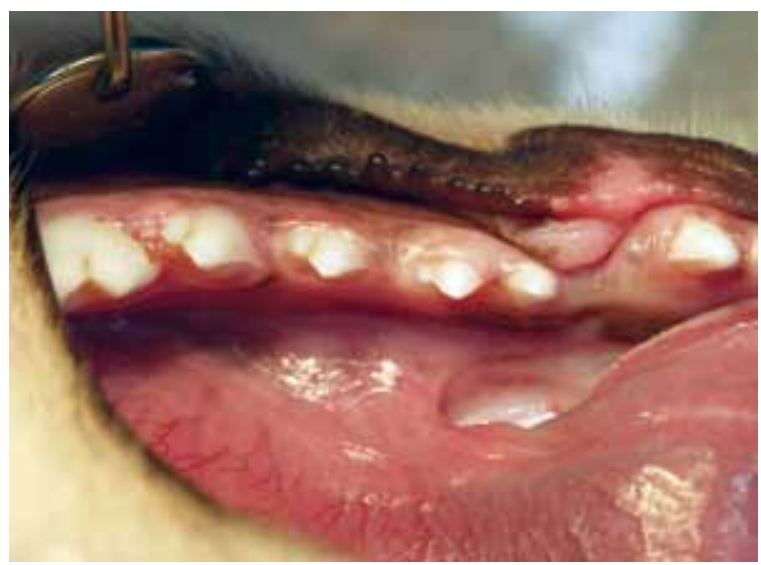

Fig. 2: Intraoral photograph indicating no observable defects on the erupted teeth

\section{DISCUSSION}

Pulpectomy of deciduous molars is perhaps considered a great challenge to dental practitioners due to the bizarre morphology of the canal systems in these teeth, as well as associated difficulties in patient management. ${ }^{8}$ In addition, when the carious process progresses faster than the developing of reactionary dentin, blood vessels of the pulp widen, and dispersed inflammatory cells become apparent. ${ }^{6}$ While increased incidence of minor hypoplasia has been reported in the permanent successor teeth following the treatment of the root canals of the deciduous teeth in some cases, ${ }^{19}$ other studies have not corroborated such an impact, concluding that these defects may have actually been engendered by some infection developed prior to pulpectomy and not induced by the procedure itself. ${ }^{20}$ This study assessed the clinical effect of pulpectomy of deciduous teeth using electrosurgery on the permanent successor teeth and showed that electrosurgery seems to have no considerable effects on permanent teeth.

Various methods have already been used for root canal preparation in deciduous teeth. Cleaning and shaping with hand files is considered as a routine technique. ${ }^{2}$ Rotary systems may be used for decreasing the working time, too. ${ }^{9-12}$ Also, the laser method may have the advantage of reduced time for instrumentation when compared with both rotary or hand instrumentation techniques. ${ }^{5}$ Decreasing the working time may stand the main comparative superiority of electrosurgical pulpectomy, which calls for evaluation in further studies.

An essential step prior to pulpectomy in deciduous teeth is determining the working length. Periapical radiography is the most widely used method for measuring the working length in these teeth. This method's reliability nonetheless could be questioned on grounds of the various degrees of root resorption in deciduous teeth, ${ }^{2}$ and, therefore, the electronic apex locators have been advocated by some studies for determination of

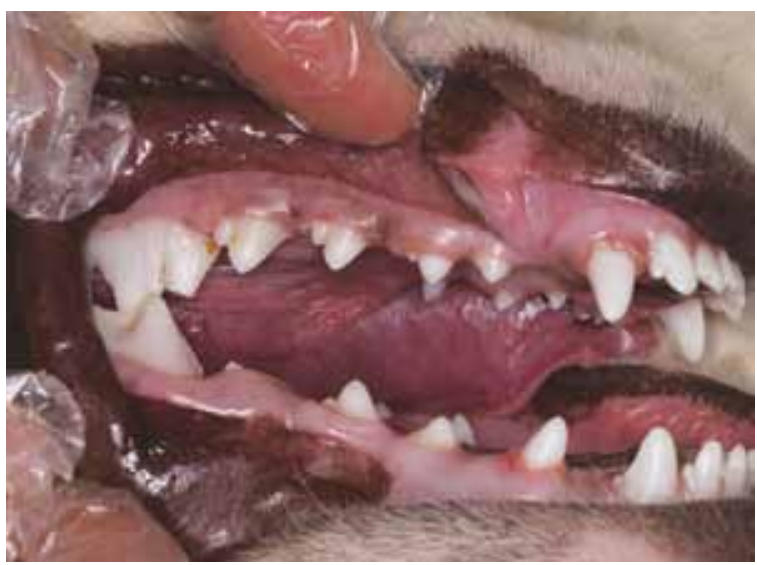

Fig. 3: Intraoral photograph indicating no observable defects on the erupted teeth

working length in deciduous teeth. ${ }^{21}$ Despite earlier comments and the fact that these electronic devices may be more convenient to both the clinician and the child, the present study followed the routine protocol to establish working length.

There are some concerns regarding the usage of electrosurgery, among which the heat generated in the course of electrosurgery and the consequent risk of damage to the adjacent tissues is a major one. ${ }^{6}$ Azzi et $\mathrm{al}^{22}$ assessed the effect of electrosurgery on the alveolar bone during periodontal surgeries and showed that the extent of bone destruction caused by electrosurgery was greater than that observed in surgical sites not exposed to the electrosurgery. Besides, healing was delayed in the electrosurgically treated areas. It should be noted that both the time length and the area electrosurgery is used for is different in periodontal surgeries from pulpectomy of deciduous teeth and, thus further studies should assess the side effects of electrosurgery on periodontal ligament and bone tissues. For increased safety, use of plastic saliva ejectors, mirrors, and evacuator tips is recommended. ${ }^{6}$ Also, the possibility of the electrode extruding beyond the root canal into the periapical tissues and the detrimental effect it can produce should be seriously taken into account.

The present study might be considered a pioneering research on the account that no similar published studies are available on using electrosurgery for pulpectomy of deciduous teeth. Therefore, it is not possible to compare the results of the present study with those of previous studies.

This study demonstrates the absence of defects in permanent tooth following an electrosurgical pulpectomy, and that these defects usually relate to infection, ${ }^{23}$ and are not an incidental feature of this procedure. Strictly speaking, it only indicates the lack of direct damage caused by electrosurgery. To confirm the results of this study, human studies are required. Also, to suggest this 
method for routine application, further studies on other parameters, such as pain, pathological resorption, etc. appear to be essential.

\section{CONCLUSION}

The usage of electrosurgery for pulpectomy of deciduous teeth seems to have no adverse effects, including enamel hypoplasia or change of the color, on succedaneous teeth. However, more investigation as to identify less timeconsuming pulpectomies for deciduous teeth shall be of great value.

\section{ACKNOWLEDGMENT}

The authors would like to thank the Vice Chancellor for Research of Mashhad University of Medical Sciences for their technical and financial supports.

\section{REFERENCES}

1. Casamassimo PS, Fields HW, McTigue DJ, Nowak AJ. Pediatric dentistry, infancy through adolescence. Philadelphia: Elsevier Saunders Co, 2013.

2. Pinkham JR, Casamassimo PS, Fields HW, McTigue DJ, Nowak AJ. Pediatric dentistry: infancy through adolescence. St Louis: Elsevier, 2005.

3. Rosendahl R, Weinert-Grodd A. Root canal treatment of primary molars with infected pulps using calcium hydroxide as a root canal filling. J Clin Pediatr Dent 1995;19(4):255-258.

4. Ramar K, Mungara J. Clinical and radiographic evaluation of pulpectomies using three root canal filling materials: an in-vivo study. J Ind Soc Ped Prev Dent 2010;28(1):25-29.

5. Soares F, Varella CH, Pileggi R, Adewumi A, Guelmann M. Impact of Er, Cr:YSGG laser therapy on the cleanliness of the root canal walls of primary teeth. J Endod 2008;34(4):474-477.

6. Hargreaves KM, Cohen S. Cohen's pathways of the pulp. St Louis: Mosby Elsevier, 2011.

7. Ochoa-Romero T, Mendez-Gonzalez V, Flores-Reyes H, Pozos-Guillen AJ. Comparison between rotary and manual techniques on duration of instrumentation and obturation times in primary teeth. J Clin Pediatr Dent 2011;35(4):359-363.

8. Ahmed HM. Anatomical challenges, electronic working length determination and current developments in root canal preparation of primary molar teeth. Int Endod J 2013;46(11):1011-1022.

9. Crespo S, Cortes O, Garcia C, Perez L. Comparison between rotary and manual instrumentation in primary teeth. J Clin Pediatr Dent 2008;32(4):295-298.
10. Kummer TR, Calvo MC, Cordeiro MM, de Sousa Vieira R, de Carvalho Rocha MJ. Ex vivo study of manual and rotary instrumentation techniques in human primary teeth. Oral Surg Oral Med Oral Pathol Oral Radiol Endod 2008;105(4): e84-92.

11. Cheung GS, Liu CS. A retrospective study of endodontic treatment outcome between nickel-titanium rotary and stainless steel hand filing techniques. J Endod 2009;35(7): 938-943.

12. Azar MR, Mokhtare M. Rotary Mtwo system versus manual K-file instruments: efficacy in preparing primary and permanent molar root canals. Ind J Dent Res 2011;22(2): 363-368.

13. Canoglu H, Tekcicek MU, Cehreli ZC. Comparison of conventional, rotary, and ultrasonic preparation, different final irrigation regimens, and 2 sealers in primary molar root canal therapy. Pediatr Dent 2006;28(6):518-523.

14. Da Costa CC, Kunert GG, Da Costa Filho LC, Kunert IR. Endodontics in primary molars using ultrasonic instrumentation. J Dent Child 2008;75(1):20-23.

15. Shaw DW, Sheller B, Barrus BD, Morton TH Jr. Electrosurgical pulpotomy-a 6-month study in primates. J Endod 1987;13(10):500-505.

16. El-Meligy O, Abdalla M, El-Baraway S, El-Tekya M, Dean JA. Histological evaluation of electrosurgery and formocresol pulpotomy techniques in primary teeth in dogs. JClin Pediatr Dent 2001;26(1):81-85.

17. Dean JA, Mack RB, Fulkerson BT, Sanders BJ. Comparison of electrosurgical and formocresol pulpotomy procedures in children. Int J Pediatr Dent 2002;12(3):177-182.

18. Bahrololoomi Z, Moeintaghavi A, Emtiazi M, Hosseini G. Clinical and radiographic comparison of primary molars after formocresol and electrosurgical pulpotomy: a randomized clinical trial. Ind J Dent Res 2008;19(3):219-223.

19. Holan G, Topf J, Fuks AB. Effect of root canal infection and treatment of traumatized primary incisors on their permanent successors. Dent Traumatol 1992;8(1):12-15.

20. Coll JA, Sadrian R. Predicting pulpectomy success and its relationship to exfoliation and succedaneous dentition. Pediatr Dent 1996;18(1):57-63.

21. Leonardo MR, Da Silva LA, Nelson-Filho P, Da Silva RA, Lucisano MP. Ex vivo accuracy of an apex locator using digital signal processing in primary teeth. Pediatr Dent 2009;31(4):320-322.

22. Azzi R, Kenney EB, Tsao TF, Carranza FA Jr. The effect of electrosurgery on alveolar bone. J Periodontol 1983;54(2): 96-100.

23. Kalra N, Sushma K, Mahapatra GK. Changes in developing succedaneous teeth as a consequence of infected deciduous molars. J Ind Soc Ped Prev Dent 2000;18(3):90-94. 